\title{
BELEZA, BELEZA E NADA MAIS ${ }^{1}$
}

\section{Denilson Lopes ${ }^{2}$}

Universidade Federal do Rio de Janeiro

\section{Resumo}

O artigo aborda a possibilidade de uma estética para o momento contemporâneo. O artigo estabelece um diálogo entre Estudos Culturais, a Escola de Frankfurt, Pragmatismo e Pós-estruturalismo com o objetivo principal de propor uma estética de comunicação em que a cultura de massa não é apenas vista como mercadoria, mas como forma de experiência. Palavras- chaves: estética; comunicação; experiência.

\section{Um manifesto}

A estética entedida a partir do século XVIII como estudo do belo e da arte se viu logo bombardeada nas suas pretensões universais e abstratas. A estética foi banida, colonizada pela política e pela economia, isolada nas suas próprias referências. O que me interessa no momento é menos falar da fragilidade do valor e da heterogeneidade contemporânea, como nos apontaram diferentes autores ao fazerem a crítica de uma estética universal e abstrata, mas certamente colocar a estética como possibilidade de existência, práticas do sujeito, portanto uma ques-

\begin{tabular}{|l|l|l|l|l|}
\hline Ilha do Desterro & Florianópolis & no 51 & p.165-181 & jul./dez. 2006 \\
\hline
\end{tabular}


tão de como intervir no mundo, uma questão ética (ver HUNTER, I.: 1992, 347372; YÚDICE, G.: 1989 e 1997; MARQUES, R. e VILELA, L. H.: 2002).

A recuperação da estética na atualidade passa pela aproximação da arte com a vida cotidiana, marcada pelas imagens midiáticas, estas fundamentais para entender a cultura contemporânea não só ao se falar das condições de produção e de recepção, mas na análise da mensagem, do produto, da obra. Este é meu ponto de partida; o que chamarei de uma estética da comunicação.

Há uma diversidade de sentidos na forma como o termo estética da comunicação vem sendo utilizado, desde a tradução do impacto das novas tecnologias da comunicação até o processo generalizado da estetização da vida cotidiana, presente no trabalho de Michel Maffesoli (ver GUIMARÃES, C.: 1997) e Mike Feathrestone. Interessa reafirmar, seguindo um filão pragmatista (ver DEWEY, J.: 1958; PARRET, H.: 1998 e SHUSTERMAN, R.: 1998), a necessidade de resgatar o afetivo, o corporal, como possibilidade de comunicação, para além de posições meramente intelectualistas, construtivistas e cerebrais, tão presentes na teoria e produção marcadamente modernas que isolaram a arte da vida.

Na perspectiva de uma estética da comunicação é fundamental diluir cada vez mais as fronteiras entre arte erudita, popular e massiva, desconstruir o dualismo experimental e comercial, fazer dialogar objetos de valor estético com produtos culturais, não para deixar de considerá-los apenas como mercadorias dentro de uma indústria cultural, mas para reafirmar a centralidade da reprodutibilidade técnica da imagem como central para pensar a arte do século $X X$, para além de qualquer visão instrumental da comunicação, colocando-a na esfera da possibilidade de compartilhamento de experiência e não simples troca de informações (ver RODRIGUES, A.: 2000).

Desta forma, pensar uma obra artística como fenômeno comunicacional implica situá-la em diálogo não só com o solo histórico, como já o fazem há muito tempo os estudos de sociologia da cultura e da arte, notadamente de vertente marxista, mas implodir a dualidade arte e sociedade e resssituá-la num fluxo de discursos, imagens e pro- 
cessos que transitam social e temporalmente, como uma narrativa que traduz a experiência contemporânea. Ao considerar as imagens como narrativas, vamos além das considerações marcadas pela indústria cultural, sem nos isolarmos em visões formalistas à medida que elas se tornam experiências dos sujeitos contemporâneos.

Mas antes de precisarmos a compreensão da obra de arte como uma narrativa, seria importante entender a abertura que o termo experiência possibilita. Ainda que seja imediata na percepção, a experiência $^{3}$ traz uma estória, uma verdade, não a verdade, que é sempre mediada por discursos sociais (SCOTT, J.: 1999, 42). A partir dos estudos culturais e dos estudos de gênero, a experiência não só se insere num solo sócio-histórico, mas se constitui como a encarnação, a narrativização de identidades, transita por elas. Identidade que deve ser vista não só como questão lógica, formal, filosófica, mas sobretudo histórica, social e política. A experiência, lembrando Joan Scott, não é origem de explicação, evidência autorizada, mas o que buscamos explicar, sobre o qual se produz conhecimento (idem, 27), que nos diz que é importante refletir sobre quem fala (idem, 31). Há mesmo uma convergência entre os Estudos Culturais e o Pragmatismo ao enfatizar que a experiência ocorre sempre em um espaço relacional (DEWEY, J.: 1958, 44), sendo uma forma de compartilhar, uma possibilidade de diálogo.

Em contraponto a esta visão, digamos comunicacional, da experiência, seria importante dialogá-la com outra tradição que podemos chamar de trágica. A experiência para Foucault $(1994,43)$ não é um olhar reflexivo sobre um objeto qualquer do vivido, que se defronta com o cotidiano na sua forma transitória para lhe retirar significações e encontra o sujeito que se é como efetivamente fundador nas suas funções transcendentais. Também se diferencia de uma tradição pragmatista, em que a experiência é conhecimento acumulado e contínuo de eventos passados, que necessita de estabilidade e descanso para se concretizar (ver DEWEY, J.: 16/7) e implica uma satisfação nas lutas e conquistas (idem, 19) do presente. Foucault se insere mais na tradição de Bataille, Nietzsche e Blanchot, para quem a experiência é tentar atingir um certo ponto da vida que seja o mais próximo possível do "invivível", 
que requer um máximo de intensidade e ao mesmo tempo de impossibilidade, talvez como para Walter Benjamin, que requer muitas vezes fazer tábula rasa para que possamos ir para a frente $(1985,116)$. A experiência tem por função retirar o sujeito de si mesmo, de fazer com que ele não seja mais o mesmo. A experiência revela e oculta, tem espaços de luz e de sombras. A experiência não é apreendida para ser repetida, simplesmente, passivamente transmitida; ela acontece para migrar, recriar, potencializar outras vivências, outras diferenças. Há uma constante negociação para que ela exista, não se isole. Aprender com a experiência é sobretudo fazer daquilo que não somos, mas poderíamos ser, parte integrante de nosso mundo. A experiência é mais vidente que evidente, criadora que reprodutora.

A experiência é o que resta quando as grandes idéias, os grandes pensadores não satisfazem mais; são as brechas abertas em sistemas demasiado acabados, fechados ou que se tornam fechados, ortodoxias para crentes, cacoetes para epígonos. A liberdade do caminho, das infidelidadades e traições teóricas, dos deslocamentos institucionais, das derivas existenciais, dos encontros ocasionais e inesperados. Com medo, com riscos. Não se trata apenas de desaprender, de jogar com o saber cristalizado, incrustado. Nem também lembrar o já vivido, mas a atenção desatenta pelo momento. $\mathrm{O}$ ar que entra limpando a poeira. $\mathrm{O}$ vento que passa e já esquecemos. Dançar e cantar no meio da chuva. Tal experiência é instável, impressão, rastro, vestígio; não é a de um sujeito isolado, nem da linguagem sem sujeito, mas das coisas, da matéria, do encontro. A palavra solidária, compartilhada, mesmo quando não possa ser narrada. Na tensão presente entre as diversas acepções sobre a experiência, apostamos na experiência, que refaz mesmo a teoria, pela narrativa.

A partir de Walter Benjamin (1985, 165-196), em seu famoso ensaio "O Narrador", poderíamos pensar no declínio da narrativa e da dificuldade de intercambiar experiências, associado à reprodutibilidade técnica da imagem e à ascensão da informação; após o impacto da televisão e da proliferação de novas tecnologias, trata-se menos de falar em declínio do que em transformação, possibilidade aventada tam- 
bém por Benjamin (1985, 114-119) em outro contexto, no ensaio "Experiência e Pobreza", ao problematizar a noção de experiência apenas como mero acúmulo de memória, de forma linear, e defender a descontinuidade e o esquecimento como empobrecimento necessário da experiência, para que se tenha um olhar menos nostálgico diante do presente. O que Benjamin desvaloriza, Silviano Santiago considera como núcleo do que podemos chamar de uma experiência contemporânea. Ao invés de tensionar experiência e o acontecimento (como GONZALEZ, H.: 1998, 101), Santiago valoriza o acontecimento como centralidade do presente marcado pela imagem e pelo desejo, em que o observar é uma experiência (SANTIAGO, S.: 1989, 38-52).

A experiência se faz imagem a ser narrada, compartilhada. Ao considerar a imagem como experiência ou falarmos em experiência audio-visual, estamos em um horizonte em que as linguagens se cruzam e convergem tecnologicamente, tanto na produção quanto em uma recepção cada vez mais marcada por uma simultaneidade de meios e sensações. Se houve um momento em que o grande dilema estava em definir as linguagens literária, fotográfica, cinematográfica e assim por diante, parece-nos mais rentáveis os espaços de intersecção, já pensados em termos como multimídia, recorrente na tradição experimental das instalações e performances, e entre-imagens (ver BELLOUR, R.: 1997, 14-17), para definir este espaço de passagens e transformação de imagens e narrativas.

Talvez a imagem nos leve a um outro tipo de experiência que mal vislumbramos, mas não creio que seja a volta a uma dimensão trágica da modernidade, na esteira de Blanchot e outros, mas certamente teríamos que aprender com a arte. "A escrita da arte abre para uma experiência em que a interpretação se dá sobre um fundo de indeterminação", afastando-se da comparação da obra de arte com a conversação, marcando uma diferença radical entre a comunicação oral, reversível, instituída no elemento da língua natural, entre locutores, e a instituída, por meio das linguagens de arte, entre um criador e um fruidor (LUZ, R.: , 98).

Neste horizonte, pretendo pensar em que medida as imagens contemporâneas são narrativas complexas de nossa época. O uso da narra- 
tiva como ato social tensiona a demanda mercadológica por um contato maior com o público já marcado pela espetacularização do privado e a demanda de sujeitos, movimentos e práticas plurais em busca de uma sociedade que se pretenda multicultural e democrática.

$\mathrm{O}$ ato de narrar implica o uso afetivo da imagem como aproximação entre obra e público, em um contexto indissociado do mercado, que não deixa as obras aprisionadas no lugar comum e no clichê, mas joga com estes elementos para elaboração de produtos com uma pluralidade semântica. A narrativa deixa de ser algo desvalorizado como espaço dos estereótipos, associado a produções comerciais e convencionais, como no clássico ensaio de Laura Mulvey, "Prazer Visual e Cinema Narrativo" (in XAVIER, I.: 1991, 435-454). O fascínio visual, como nos lembra Steven Shaviro, seria não uma "compulsão irresistível, passiva" (8), uma "fixação estabilizadora", mas uma "mobilidade incansável" (9) . No horizonte das ambigüidades pós-modernas, em que o novo e o choque deixam de ser marcas de ruptura para se tornarem estratégias de marketing e da produção da notícia, a narrativa e o fascínio da imagem ganham um novo interesse.

De que estética ainda podemos falar e é dela que quero falar, não só de crítica, leitura, interpretação de obras. Uma estética, sem dúvida localizada e engajada num tempo e numa sociedade, ao invés de abstrata e universal, que emerge do embate com as obras mas procura confrontá-las, compará-las, estabelecer séries, linhagens, a partir de problemas, conceitos, categorias. Uma estética pop ${ }^{4}$, que não tem medo do fácil, da redundância informativa, do descartável, do afetivo e coloca no mesmo lugar o que antes chamávamos de popular e erudito. Uma estética híbrida, intertextual, transemiótica, multimidiática. Longe estão as querelas por definir linguagens artísticas e campos do conhecimento, que só interesssam aos burocratas do pensamento encastelados no poder que a especialização pode lhes conferir. Uma estética centrada na experiência, palavra ardilosa, múltipla, que traz uma tensão constante entre a possibilidade de acúmulo, transmissão, comunicação e conversação ou/e sua impossibilidade. Esta experiência está sempre além da arte mas afirma o lugar desta como forma de conhecimento e 
de estar no mundo. Uma estética da comunicação, não dos meios de comunicação. Mas quando nosso cotidiano se transformou em experiência midiática, audio-visual, o que fazer?

Uma alternativa

Pudesse um poema, um amor, pudesse qualquer esperança viver assim o engano:

beleza, beleza

beleza,

mais nada.

Eucanãa Ferraz

Que destino teria a beleza hoje em dia? Seria o de Gustav von Aschembach em Morte em Veneza? Quanto mais ele procura a beleza, mais se aproxima da morte. Seria esta impossibilidade o destino do esteta hoje em dia? Ou seria, antes, o puro prazer de voyeur perplexo, imobilizado como no poema "Sob o Duplo Incêndio", de Carlito Azevedo? Penso ainda em Beleza Americana, o filme de Sam Mendes. Lester, o protagonista, ao se encantar por Angela, amiga de sua filha Jane, larga seu emprego, começa a fazer musculação, volta a ouvir rock, procura recuperar sua juventude. Ainda que esta cena seja tratada pelo diretor como ridícula, patética, é a partir desse momento que o protagonista se modifica. No mesmo filme, o jovem Ricky é quem mais parece traduzir a possibilidade transformadora da beleza na vida cotidiana. Ele filma o que o rodeia, buscando não só ser voyeur, mas estar no mundo. Ao relatar a Jane o que de mais belo tinha filmado, um saco que por 15 minutos volteava à sua frente, ele se aproxima como nunca até então de outra pessoa. É pela beleza que acontece esta possibilidade, por breve que seja, de estar no mundo; trata-se mais de uma intensidade do que de uma elevação (LYOTARD, J.F.: 1988, 111).

Falar da beleza não é apenas um discurso inútil, me coloca, ao mesmo tempo, no mundo novamente reencantado (BAUMAN, Z.:1997, 
42 ) e na minha própria solidão, ao "reunir/cada fragmento nosso, perdido,/de dor e de delicadeza" (Carlito Azevedo, "Na Gávea" ). Ou seria este desejo, isto tudo ilusão? A beleza e nada mais sigo.

Esta busca da beleza passa primeiro pelo elogio, pelo retorno do sublime seja como programa, seja como provocação. Estaria mesmo todo sentimento de encantamento e fascínio diante do mundo, das pessoas reduzido a mero olhar de consumidor, marcado por padrões publicitários, que encobrem a realidade? É necessário mesmo uma viagem de redescoberta, de reaprendizado, sem medo da beleza uma vez mais, sem confundir estética com esteticismo, salões de beleza ou academias de musculação, uma viagem como a que o poeta Basho fez em Trilha Estreita ao Confim apenas para contemplar a lua cheia nascendo sobre as montanhas do santuário de Kasima.

Mas o que fazer quando nosso cotidiano se transformou em experiência midiática, audio-visual? Acelerar, ir mais rápido, ser mais veloz, aderir ao simulacro ou estabelecer pausas, silêncios, recolhimento? Opto agora pelo sublime. O sublime não só como uma categoria do gosto, da experiência, bastante discutida como tal dentro da história da filosofia, mas sobretudo uma categoria de articulação das obras contemporâneas.

Sem me alongar, parto de uma primeira e precária definição do sublime. O sublime seria a experiência entre horror e prazer, experiência de fascínio diante de uma paisagem, uma pessoa ou uma obra de arte, como nos lembra Nelson Brissac Peixoto (1997, 301/2), é “o impensável, o indiscernível", "evidência de algo que não podemos ver nem definir mas que nos arrebata", "desejo indeterminado e imenso", "o inomeável, inenarrável".

Para além de nos determos na trajetória desta categoria ${ }^{5}$ a partir da discussão no mundo latino (Longino, Cecílio, Plotino), nos séculos XVIII e XIX, sobretudo na filosofia alemã (Kant), no Romantismo, e mais recentemente sua retomada, entre outros, por Lyotard, só ressalto o que interessa para discutir sua atualidade hoje em dia. Para Longino (1996, 18), o sublime é "o eco da grandeza da alma"; esta aproximação do sublime com o grandioso continua para além do caráter épico presente 
nele, até em Kant $(1995,93)$, ao remeter ao absolutamente grande, ou nos românticos, ao fascínio pelo indefinido, mas já em Burke (s.d.,78 e 84), há simultaneamente a associação do sublime com a infinitude, a magnificência, mas também se abre uma outra tradição, bastante fecunda na modernidade, ao associar o sublime com o extremamente pequeno, possível de ser identificado posteriormente, por exemplo, na memória involuntária de Proust. À medida que cada vez mais o grandioso, o monumental pode ser associado à arte dos vencedores, de impérios autoritários, da arte nazista, do Realismo Socialista aos épicos hollywoodianos, éjustamente no cotidiano, no detalhe, no incidente, no menor, que residirá o espaço da resistência, da diferença.

Uma primeira aproximação seria possível entre o sublime e o sagrado. Tanto o êxtase místico quanto o sublime são marcados por uma suspensão e uma dificuldade em nomear o vivenciado, experiências que podem ser vistas como análogas ao orgasmo ${ }^{6} \mathrm{e}$ à própria busca da arte moderna em representar o irrepresentável, em transgredir os limites, transitar entre o ruído e o silêncio, explorar o fora da tela, das galerias, o fora do palco.

Mas apesar do sublime ser fruto da passagem de uma sociedade centrada em Deus e na religião como aparato institucional para uma sociedade laica, há uma perda do privilégio do encantamento diante dos santos e deuses para que o mundo material possa também ser fonte desta experiência. O sublime, afastado de um dimensão metafísica, dualista, não implica a negação do mundo, do corpo e dos sentidos em favor do espírito. Sem dúvida, se trata de uma suspensão, mas se não podemos viver em constante encantamento e fascínio, aprendemos algo desta suspensão? O que nos resta depois do gozo, a não ser talvez lembrar o sentido? Ou ainda, a experiência do sublime poderia ser imemorial em meio a transitoriedade de tudo? Sua própria força estaria não em uma transcendência, mas em um mergulho mesmo no mundo das coisas, no aqui e no agora (LYOTARD, J.F.:1988, 104).

Longe de localizar o sublime apenas numa tradição canonizadora do moderno, conservadora, nostálgica de sentidos em meio à rapidez das imagens e máscaras, como talvez seja o caso de Lyotard ao eleger o 
pintor abstrato Barnett Newman quando resgata o sublime em busca de uma "estética desnaturada, portanto negativa" $(1993,69)$, mais próxima à alta modernidade do que diante da condição pós-moderna que outrora defendia. Acredito e aposto numa linhagem do sublime, em tom menor, no cotidiano, em personagens comuns, presente na poesia de Manuel Bandeira ena crônicas de Rubem Braga, como bem a mapeou Davi Arrigucci (1990,1987), e se desdobra, num desejo de revalorização da narrativa como forma de se aproximar do público, de se aproximar do mundo contemporâneo, seja no cinema, seja na literatura, de Kiarostami, Wong Kar Wai, Kieslowski a Mike Leigh, Hal Hartley, do último Almodóvar a Terence Davies, em Kazuo Ishiguro, David Leavitt e Michael Cunninghan; entre nós, em Walter Salles e Eduardo Coutinho, Adriana Lisboa e Rubens Figueiredo. Trata-se da possibilidade de uma experiência de beleza que emerge de um cotidiano povoado de clichês, implica repensar o banal e se situa de forma tensa entre a dimensão transgressora e transcendental do sublime associado ao grandioso e o belo, marcado pelo agradável, convencional.

O sublime no banal não nega a arte, diante da dissolução provisória dos limites do sujeito. O sublime no banal não se confunde com uma busca de uma autenticidade perdida no mundo da reprodutibilidade técnica e eletrônica da imagem, da aura benjaminiana. Aproxima-se do que Ítalo Moriconi (1998) chamou de dessublimação, ao incorporar o corporal, mas talvez por não compartilhar o mesmo solo cultural de onde suas reflexões parecem emergir, marcadas pela contracultura, pelo desbunde e pela poesia marginal. Distancio-me de qualquer possibilidade iconoclástica, de virulência transgressora, mesmo que paródica. O sublime no banal estabelece mais um jogo de tensões entre a contemplação e o olhar distraído, a rapidez e a lentidão e prefere apostar mais na sutileza, na delicadeza, na leveza, nas palavras que não canso de repetir de Ana Chiara (1999), "sem muito desespero, que é inútil, sem pieguice, que é meio de mau gosto, sem cinismo, porque já basta a desrazão, mas com suave ironia para poder suportar o peso". 
Este sublime se encontra traduzido exemplarmente no último filme de Rafael França, Prelude to Announced Death, concluído pouco antes de sua morte. Abraços e toques se sucedem entre dois homens de quem não vemos os rostos. Ou é do que me lembro. Nomes atravessam a tela: não uma lista de pessoas, mas sucessão de lembranças. Na ansiedade do encontro e da despedida anunciada no título, não há mais tempo para memórias detalhadas, falas longas, elaboradas, só flashes de nomes e gestos. Nada para ser dito ou falado a não ser tocar. As pessoas restam em nomes. Antes de serem perdidos, esquecidos. Não se trata de saciar um último desejo. Não há tanto frenesi. Não há sexo, orgasmo. Apenas a superfície da pele se apresenta simplesmente, como se pudesse reter pela delicadeza, dizer.

Seria o sublime, portanto, um enobrecimento do banal, dar ênfase, foco ao que não tem? Sem dúvida, o sublime se situa no quadro em que a arte foi se tornando cada vez mais um conceito ampliado e complexo, em que a beleza se afastou de objetos específicos. Tudo pode ser belo, mesmo um cadáver, como no famoso poema de Baudelaire. Qualquer coisa pode ser arte, como nos impactou Duchamp. Todo mundo pode ser artista, como reafirmaram os punks. Mas hoje, não se trata tanto de uma militância virulenta, mas de produzir sentidos precários, recolher cacos, vestígios, habitar ruínas. Não esperar a revelação, a epifania, a iluminação, nem idealizar o simples, o cotidiano, mas certamente desmistificar o grandioso, o momumental. Desta forma, o sublime não se apresentaria como, em críticas originárias dos estudos culturais, "espaço da reconciliação burguesa", que implica a volta à estética como produtora de hierarquias e distinções (DELFINO, S. : 104), nem como "oposto ao sentimento de solidariedade social" (HEBDIGE, D.: 1998, 141) por "atomizar a sociedade ao confrontar cada indivíduo com a perspectiva de sua própria destruição iminente e solitária" (idem, 137).

O sublime seria uma experiência aristocrática? Seria mais uma experiência daqueles que têm tempo. Seria o tempo um privilégio de classe? Mas também os que têm muito dinheiro estão muitas vezes interessados em gastar seu tempo em terem mais dinheiro ou manter o que têm. O sublime certamente implica uma outra relação com o mun- 
do não marcado exclusivamente pelo trabalho e pela produção. Como produzir imagens e narrativas que ainda tenham força diante do excesso informacional? É possível falar em um "sublime tecnológico", não apenas como "objeto de uma produção controlada e de um consumo socializado" (COSTA, M.: 1995 , 49), como se as novas tecnologias por si instaurasssem um nova situação material (idem, 37), mas no momento em que os meios de comunicação de massa não são elementos externos, são cotidiano, memória e afeto, como no romance Onde Andará Dulce Veiga? de Caio Fernando Abreu, mergulhamos numa atmosfera em que o sujeito humanista se dissolve, seu excesso se esvazia.

Há mais de 20 anos, Roland Barthes falava da solidão do discurso amoroso em uma sociedade centrada cada vez mais na sexualidade. Talvez a estética tenha se tornado uma outra solidão. Todos falam de cultura, mercado. Sim, é claro que isto ajuda a compreender mas não esgota o encantamento, a perdição desta experiência: o sublime. Falar do sublime não para ter saudade de algo que nós perdemos, de canonizar e monumentalizar a alta modernidade, mas algo que podemos encontrar quando menos esperamos, sobretudo quando não esperamos mais nada. Nada de mais grandioso, transcendental, mas menor, banal, cotidiano, concreto, material. O sublime é uma alternativa tanto ao discurso fatigado das transgressões tardo-modernas que artistas perfomáticos, cineastas experimentais insistem em ressuscitar quanto diante de um mundo povoado de imagens, clichês e informações, não para recusá-lo, mas de dentro dele afirmar uma adesão ao mundo. Como nos provoca Nelson Brissac Peixoto: "o destino das imagens não está mais sendo jogado no experimentalismo da vanguarda nem no engajamento ideológico, discursos completamente integrados no sistema de produção de clichês. O futuro das imagens está na produção do sublime" (PEIXOTO, N. B.: 1997, 318). O sublime midiático, tecnológico, o sublime pop. O sublime não como fuga do mundo, escapismo, mas afirmação da possibilidade do encontro, da presença.

O sublime se constitui a base de uma educação dos sentidos a partir do precário, do fugaz, do contingente, de tudo que evanesce rápido, mas que brilha inesperada e sutilmente. Um tesouro para ser guardado. 
O sublime faz da arte uma ambiência, uma paisagem onde se pode habitar e caminhar lentamente como se houvesse o tempo todo do mundo, é a volta em torno de um lago que bem pode ser uma vida, é o retorno ao mar, ao indefinido, ao inumano. Se for engano, ilusão, que seja então. Talvez todo este esforço tenha sido em vão. Por que buscar renomear, torcer uma palavra com sentidos tão arraigados, por que não falar em outra palavra: leveza.

O sublime aqui se traduz num posicionamento ético e estético diante do mundo frente ao populismo midiático sem ignorar os meios de comunicação mas pensá-los em sua diversidade. Pensar os frágeis limites entre o sublime e o banal implica recolocar a atualidade ou não de uma estética hoje em dia. Em contraponto a um discurso da negação e de transgressão, reduzido hoje a uma estratégia de marketing, defendo uma gentil subversão. Também em contraponto a uma estética da violência, ao fascínio pelo grotesco e pelo abjeto, o sublime se traduz em leveza e delicadeza . Não consigo deixar de pensar no primeiro princípio da estética de Nietzsche (1999, 11): "O que é bom é leve, tudo divino se move com pés delicados". Mas esta já seria uma outra estória.

\section{Notas}

1. Agradeço, especialmente, as críticas e comentários de Ítalo Moriconi, Kathryn Rosenfield, Elyeser Szturm, Eucanãa Ferraz, Adriana Lisboa, Ângela Prysthon, Muniz Sodré, Ismail Xavier, Carlinda Fragale e Tânia Rivera, bem como as discussões que ampliaram as possibilidades deste trabalho feitas na Unb, UFPE, UFRJ. PUC/RJ, UERJ, UFJF e no encontro da Sociedade Brasileira de Estudos de Cinema realizada na UFF.

2. Coordenador do Programa de Pós-Graduação em Comunicação da Universidade de Brasília, presidente da Associação Brasileira de Estudos de Homocultura , autor de Nós os Mortos: Melancolia e Neo-Barroco (RJ, Sette Letras, 1999) e O Homem que amava Rapazes e Outros Ensaios (RJ, Aeroplano, 2002) e pesquisador do CNPq. No momento organiza uma coletânea sobre cinema dos anos 90 .

3. Estas reflexões foram utilizadas no meu ensaio "Experiência e Escritura", publicado no livro $O$ Homem que Amava Rapazes para refletir sobre a experiência do pesquisador no ato da escrita. 
4. Para reflexões que partem da música pop para discutir o conjunto da estética contemporânea, não-formalista, afetiva, destaco Frith (1994) e Baugh (1994), que conformam um novo mapa estético e afetivo, diferente do que Jameson (1996) chama de esmaecimento de afetos, de afetos auto-sustentados e impessoais, marcados por uma certa euforia, por uma intensidade esquizofrênica valorizadora do presente e uma falta de memória; bem como do que Grossberg chamou de "colapso da relação entre afeto e sentido", em que as experiências afetivas não estariam mais ancoradas em mapas sociais, incapazes de organizar nossas vidas (1992, 1997).

5. Para uma discussão mais filosófica entre nós, ver, por exemplo, Rodrigo Dantas (1998).

6. Sendo comum o uso de metáforas eróticas na literatura mística e de metáforas sacras na literatura erótica.

\section{Referências}

AGEL, Henri. El Cine y lo Sagrado. Madri: Rialp, 1960. . O Cinema tem Alma? Belo Horizonte: Itatiaia, 1963.

ARRIGUCCI, Davi. "Ensaio sobre 'Maçã' (Do Sublime Oculto)" in Humildade, Paixão e Morte. A Poesia de Manuel Bandeira. São Paulo: Companhia das Letras, 1990.

. Enigma e Comentário. São Paulo: Companhia das Letras, 1987.

AZEVEDO, Carlito. Sublunar. (1991-2001). Rio de Janeiro: 7 Letras, 2001.

BASHO. Trilha Estreita ao Confim. São Paulo: Iluminuras, 1997.

BAUGH, Bruce. "Prolegômenos a uma Estética do Rock". Novos Estudos-CEBRAP, 38, março 1994.

BAUMAN, Zygmunt. Ética pós-moderna. São Paulo: Paulus, 1997.

BELLOUR, Raymond. Entre-imagens. Campinas: Papirus, 1997.

BENJAMIN, Walter. Magia e Técnica, Arte e Política. São Paulo: Brasiliense, 1985. 
BLANCHOT, Maurice. O Espaço Literário. Rio de Janeiro: Rocco, 1987.

. A Parte do Fogo. Rio de Janeiro: Rocco, 1997.

BURKE, Edmund. Uma Investigação Filosófica sobre a Origem de Nossas Idéias do Sublime e do Belo. Campinas: Papirus, 1993.

CAIAFA, Janice. Nosso Século XXI. Rio de Janeiro: Relume-Dumará, 2000 .

CANCLINI, Néstor García. Culturas Hibridas. São Paulo: Edusp, 1997.

CHIARA, Ana. "Geografia dos Afetos" in MORICONI, Ítalo (org.). Op. Cit. MORICONI, Ítalo (org.). Caio Fernando Abreu - Palavra e Pessoa. Manuscrito Inédito, 1999.

COSTA, Mario. O Sublime Tecnológico. São Paulo: Experimento, 1995.

DANTAS, Rodrigo (org.). Belo, Sublime e Kant. Belo Horizonte: Ed. UFMG, 1998.

DEWEY, John. Art as Experience. New York: Capricorn, 1958.

DELFINO, Sílvia. "La Trivialidad de lo Sublime". XYZ - Revista de Comunicación, I, 1, febrero 1997.

DYER, Richard. Only Entertainment. Londres: Routledge, 1992.

FERRATER MORA, José. Diccionario de Filosofía. Barcelona: Ariel, 1994.

FERRAZ, Eucanâa. Desassombro. Rio de Janeiro: 7 Letras, 2002.

FOUCAULT, Michel. Dits et Ecrits. Vol. 4 (1980.1988). Paris: Gallimard, 1994.

FRITH, Simon. "Towards an Aesthetics of Popular Music" in LEPPERT, Richard e McCLARY, Susan (orgs.). Music and Society. Cambridge: Cambridge University Press, 1994.

GONZALES, Horacio. "Experiencia y Acontecimiento. Cinco Aforismos", La Invencion y La Herencia. Cuadernos Arcis, 6, junho 1998.

GROSSBERG, Lawrence. "Ideology and Affective Epidemics" in We Gotta Get out of this Place. New York/London: Routledge, 1992. 
.Postmodernity and Affect: All Dressed up with no Place to Go" in Dancing in Spite of Myself. Essays on Popular Culture. Durham/London: Duke University Press, 1997.

GUIMARÃES, César. "Para Compreender a Experiência Estética", Anais do 7. Encontro Nacional da Compós, PUC-SP, 1997.

HEBDIGE, Dick. "El Objeto Impossible: hacia una sociología de lo sublime" in CURRAN, James et al. (orgs.). Estudios Culturales y Comunicación. Barcelona/ Buenos Aires/México: Paidós, 1998.

HUNTER, Ian. "Aeshetics and Cultural Studies" in GROSSBERG, Lawrence et al. (orgs.). Cultural Studies. New York/London: Rourledge, 1992.

JAMESON, Fredric. Pós-Modernismo. A Lógica Cultural do Capitalismo Tardio. São Paulo: Ática, 1996.

KANT, Emmanuel. Crítica da Faculdade de Juízo. 2 ed. Rio de Janeiro: Forense, 1995. . Observações sobre o Sentimento do Belo e do Sublime. 2ed. Campinas: Papirus, 2000.

LONGINO. Do Sublime. São Paulo: Martins Fontes, 1996.

LOPES, Denilson. "Experiência e Escritura" in O Homem que Amava Rapazes e Outros Ensaios. Rio de Janeiro: Aeroplano, 2002.

LUZ, Rogério. Filme e Subjetividade. Rio de Janeiro: Rios Ambiciosos, 2002.

LYOTARD, Jean François. L'Inhumain. Paris: Galilée, 1988. . Lições sobre a Analítica do Sublime. Campinas: Papirus, 1993.

MARQUES, Reinaldo e VILELA, Lúcia Helena (orgs.). Valores. Belo Horizonte: Ed.UFMG/Abralic, 2002.

MORICONI, Ítalo. "Quatro (2 + 2) Notas sobre o Sublime e a Dessublimação", Revista Brasileira de Literatura Comparada, 4, 1998. . "Pós-Modernismo e a Volta do Sublime" in PEDROSA, Célia et al. (orgs.). Poesia Hoje. Niterói: Eduff, 1998. 
MULVEY, Laura. "Prazer Visual e Cinema Narrativo" in XAVIER, Ismail (org.). A Experiência do Cinema. 2 ed. Rio de Janeiro: Graal, 1991.

NIETZSCHE, Friederich. O Caso Wagner. Nietzsche contra Wagner. São Paulo: Companhia das Letras, 1999.

PARENTE, André. Narrativa e Modernidade. Campinas: Papirus, 2000.

PARRET, Herman. Estética da Comunicação. Campinas: Ed. da Unicamp, 1998.

PEIXOTO, Nelson Brissac. "Ver o Invisível: a Ética das Imagens" in NOVAES, Adauto (org.). Ética. 5 reimpressão. São Paulo: Companhia das Letras, 1997.

RODRIGUES, Adriano. "Comunicação e Experiência”, Anais do $9^{\circ}$ Encontro Anual da Compós. Porto Alegre: PUC-RS, 2000.

ROLFE, Jeremy Gilbert. Beauty and the Contemporary Sublime. New York: Allworth, 1999.

SANTIAGO, Silviano. "O Narrador Pós-Moderno" in Nas Malhas da Letra. São Paulo: Companhia das Letras, 1989.

SCOTT, Joan. "Experiência" in SILVA, Alcione Leite da et al (orgs.). Falas de Gênero. Ilha de Santa Catarina, Mulheres, 1999, p. 42.

SHAVIRO, Steven. The Cinematic Body. 3 ed. Minneapolis: University of Minnesotta Press, 2000.

SHUSTERMAN, Richard. Vivendo a Arte. Rio de Janeiro, 34, 1998.

YUDICE, George. "Marginality and the Ethics of Survival" in ROSS, Andrew (org.). Universal Abandon? The Politics of Postmodernism. 2 ed. Minneapolis: University of Minnesota Press, 1989.

."Debates Atuais em Torno dos Estudos Culturais nos Estados Unidos", Mimeo, 1997. 